\title{
On approximating curves associated with nonexpansive mappings
}

\section{FRANCESCA VETRO}

\begin{abstract}
.
Let $X$ be a Banach space with metric $d$. Let $T, N: X \rightarrow X$ be a strict $d$-contraction and a $d$-nonexpansive map, respectively. In this paper we investigate the properties of the approximating curve associated with $T$ and $N$. Moreover, following [3], we consider the approximating curve associated with a holomorphic map $f: B \rightarrow \alpha B$ and a $\rho$-nonexpansive map $M: B \rightarrow B$, where $B$ is the open unit ball of a complex Hilbert space $H, \rho$ is the hyperbolic metric defined on $B$ and $0 \leq \alpha<1$. We give conditions on $f$ and $M$ for this curve to be injective, and we show that this curve is continuous.
\end{abstract}

Acknowledgment. The author wishes to thank the referees for useful suggestions.

\section{REFERENCES}

[1] Goebel, K. and Reich, S., Uniform Convexity, Hyperbolic Geometry and Nonexpansive Mappings, Marcel Dekker, New York, Basel, 1984

[2] Kopecká, E. and Reich, S., Asymptotic behavior of resolvents of coaccretive operators in the Hilbert ball, Nonlinear Anal. 70 (2009), 3187-3194

[3] Levenshtein, M. and Reich, S., Approximating fixed points of holomorphic mappings in the Hilbert ball, Nonlinear Anal. 70 (2009), 4145-4150

[4] Nadler, S. B. and Ushijima, K., Fixed point curves for linear interpolations of contraction maps, Appl. Anal. 29 (1988), 165-176

[5] Reich, S., Strong convergence theorems for resolvents of accretive operators in Banach spaces, J. Math. Anal. Appl. 75 (1980), 287-292

[6] Vidalis, T., Fixed point curves generated by nonexpansive mappings, Fixed Point Theory 6 (2005), No. 2, 333-339

DiPARTIMENTO Di MATEMATICA E INFORMATICA

UNIVERSITÀ DEGLI STUDI DI PALERMO

Via ARCHIRAFi 34, 90123 PAlERMo, ITALY

E-mail address: fvetro@math. unipa.it

Received: 21.07.2009; In revised form: 17.10.2010; Accepted: 23.02.2011

2000 Mathematics Subject Classification. 54H25, 47H09, 47H10.

Key words and phrases. Approximating curve, fixed point, contractive mapping, nonexpansive mapping, hyperbolic metric, holomorphic mapping. 